\title{
Article \\ Effects of Lysine $N$ - $\zeta$-Methylation in Ultrashort Tetrabasic Lipopeptides (UTBLPs) on the Potentiation of Rifampicin, Novobiocin, and Niclosamide in Gram-Negative Bacteria
}

\author{
Linus Schweizer ${ }^{1,+} \mathbb{D}$, Danyel Ramirez ${ }^{2,+}$ and Frank Schweizer $2,3, *$ \\ 1 Department of Laboratory Medicine and Pathobiology, University of Toronto, Toronto, ON M5S 1A8, Canada; \\ linus.schweizer@mail.utoronto.ca \\ 2 Department of Chemistry, University of Manitoba, Winnipeg, MB R3T 2N2, Canada; \\ ramiredm@myumanitoba.ca \\ 3 Department of Medical Microbiology and Infectious Diseases, University of Manitoba, \\ Winnipeg, MB R3E 0J9, Canada \\ * Correspondence: frank.schweizer@cc.umanitoba.ca \\ + These two authors contributed equally in this work.
}

\section{check for}

updates

Citation: Schweizer, L.; Ramirez, D.; Schweizer, F. Effects of Lysine $N$-乙-Methylation in Ultrashort Tetrabasic Lipopeptides (UTBLPs) on the Potentiation of Rifampicin, Novobiocin, and Niclosamide in Gram-Negative Bacteria. Antibiotics 2022, 11, 335. https://doi.org/ 10.3390/antibiotics11030335

Academic Editors: Paul Robert

Hansen and Henrik Franzyk

Received: 31 January 2022

Accepted: 2 March 2022

Published: 3 March 2022

Publisher's Note: MDPI stays neutral with regard to jurisdictional claims in published maps and institutional affiliations.

Copyright: () 2022 by the authors Licensee MDPI, Basel, Switzerland. This article is an open access article distributed under the terms and conditions of the Creative Commons Attribution (CC BY) license (https:/ / creativecommons.org/licenses/by/ $4.0 /)$.

\begin{abstract}
Outer membrane (OM) drug impermeability typically associated with a molecular weight above $600 \mathrm{Da}$ and high hydrophobicity prevents accumulation of many antibiotics in Gram-negative bacteria (GNB). Previous studies have shown that ultrashort tetrabasic lipopeptides (UTBLPs) containing multiple lysine residues potentiate Gram-positive bacteria (GPB)-selective antibiotics in GNB by enhancing OM permeability. However, there is no available information on how $N$-substitution at the $\zeta$-position of lysine in UTBLPs affects antibiotic potentiation in GNB. To study these effects, we prepared a series of branched and linear UTBLPs that differ in the degree of $N$ - $\zeta$-methylation and studied their potentiating effects with GPB-selective antibiotics including rifampicin, novobiocin, niclosamide, and chloramphenicol against wild-type and multidrug-resistant GNB isolates. Our results show that increasing $N-\zeta$-methylation reduces or abolishes the potentiating effects of UTBLPs with rifampicin, novobiocin, and niclosamide against GNB. No trend was observed with chloramphenicol that is largely affected by efflux. We were unable to observe a correlation between the strength of the antibiotic potentiating effect to the increase in fluorescence in the $1-N$-phenylnaphthylamine (NPN) OM permeability assay suggesting that other factors besides OM permeability of NPN play a role in antibiotic potentiation. In conclusion, our study has elucidated crucial structure-activity relationships for the optimization of polybasic antibiotic potentiators in GNB.
\end{abstract}

Keywords: outer membrane permeabilizer; antibiotic potentiator; antibiotic adjuvant; novobiocin; rifampicin; niclosamide; Pseudomonas aeruginosa; Acinetobacter baumannii; Escherichia coli

\section{Introduction}

Bacterial resistance to antibiotics is a major global health problem [1]. Currently, carbapenem-resistant Pseudomonas aeruginosa (CRPA), carbapenem-resistant Acinetobacter baumannii (CRAB), and carbapenem-resistant Enterobacteriaceae (CRE) are among the priority pathogens that pose the greatest threat to human health [2,3]. These Gram-negative bacteria (GNB) are frequently multidrug-resistant (MDR) and have become resistant to most antibiotics. Despite large investments into antibiotic discovery, no new drug class with novel modes of action against GNB has been approved in 50 years [4,5]. This failure is caused by intrinsic resistance mechanisms that prevent antibiotics from achieving the necessary intracellular concentration required to induce cell death [6]. Two major resistance mechanisms, low outer membrane $(\mathrm{OM})$ permeability and efflux, control the intra-bacterial concentration of antibiotics in GNB [6,7]. In contrast to Gram-positive bacteria (GPB), GNB possess two membranes with orthogonal permeability [7]. The OM, characterized by the 
presence of a highly polar hydrophilic coat of lipopolysaccharides (LPS) in the outer leaflet and polar porin channels, permits the passage of only polar and low molecular weight compounds below $600 \mathrm{Da}$. In contrast, the inner membrane, devoid of LPS, typically requires non-polar and hydrophobic molecules for efficient lipid bilayer permeation [7]. Moreover, the passage of molecules through the $\mathrm{OM}$ is a rather slow process that when combined with elevated expression of multidrug efflux pumps, the intracellular concentration of antibiotics becomes synergistically reduced [6,7]. Recently, predictive compound accumulation rules for antibiotics have emerged for GNB like Escherichia coli [8]. Computational analysis of results revealed that compounds are most likely to accumulate within the cell containing one or more (primary) amino functions, and which are amphiphilic and rigid (low globularity) [8]. Unfortunately, these accumulation rules do not apply to intrinsically resistant organisms and bacteria with elevated expression of multidrug efflux pumps [8].

The OM permeability constraints of GNB prevent many hydrophobic antibiotics with a molecular weight above $600 \mathrm{Da}$ from accumulating in the cell effectively. GPB-selective antibiotics such as rifampicin (RIF), novobiocin (NOV), niclosamide (NIC), and others are inactive against GNB for this reason [6,7]. However, the apparent OM impermeability of many GPB-selective antibiotics can be overcome with the use of helper molecules termed OM permeabilizers (OMPs) [9]. Ideal OMPs typically possess low antibacterial activity that is hypothesized to prevent rapid resistance development [6]. An interesting feature of OMPs is its synergistic relationship with GPB-selective antibiotics. It is theorized that OMPs destabilize the $\mathrm{OM}$, resulting in an increase of the intra-bacterial concentration of antibiotics, thereby potentiating the antibacterial effect of the GPB-selective antibiotic. However, the synergistic effect of the GPB-selective antibiotic on the OMP is not understood. Over the years, several OMPs have been described, which sensitize GPB-selective antibiotics against GNB [9]. Most of the known OMPs are amphiphilic polybasic molecules that contain hydrophobic functions, and two or more basic amino or guanidino functions. Examples include peptidic OMPs derived from the polymyxin family $[9,10]$, antimicrobial peptides [11], antimicrobial peptidomimetics [12], and amphiphilic aminoglycosides [13,14]. Recently, we have shown that ultrashort tetrabasic lipopeptides (UTBLPs) sensitize GPBselective antibiotics against GNB [15]. For instance, it was possible to reduce the minimal inhibitory concentration (MIC) of RIF and NOV in combination with UTBLPs against CRPA, $\mathrm{CR} A B$, and $\mathrm{CRE}$ to concentration levels that can be achieved in human blood, indicating that antibiotic + OMP combinations may possess therapeutic potential [15]. Moreover, preclinical and clinical investigations are in support for further validation of the antibiotic + OMP combination strategy [16,17]. For example, the human safety and pharmacokinetics of polymyxin-derived tribasic lipopeptide SPR741 were demonstrated in a Phase 1 study [18]. Perhaps the best-known OMP is PMBN, a polymyxin-based pentabasic nonapeptide devoid of the acyl chain present in polymyxins. PMBN has very weak antibacterial activity, but sensitizes many classes of antibiotics in GNB [19].

The amphiphilic character of OMPs is essential to its activity. Hydrophobicity is generally imparted by residues such as alanine, leucine, and phenylalanine among others. Incorporation of fatty acids has also been shown to enhance membrane permeabilization [20-22]. The acyl chain likely helps anchor the peptide into the OM by interacting with the lipid chains of the LPS [22]. Indeed, the presence of an acyl chain improves the activity of several antimicrobial peptides such as daptomycin, dalbavancin, and polymyxins [21,22]. Majority of polybasic OMPs contain primary amino and unsubstituted guanidino functions that impart polarity to the molecule. Peptidic polyamine-based OMPs can be rapidly generated by incorporation of diaminobutyric acid, ornithine, and lysine building blocks into peptides using solid or solution phase chemistry. Bivalent positively charged metal ions $\left(\mathrm{Mg}^{2+}\right.$ or $\left.\mathrm{Ca}^{2+}\right)$ in the outer leaflet of GNB are presumably displaced by the positively charged amino groups in polyamine-based OMPs, resulting in a transient destabilization of the LPS packing of the OM, and subsequent facilitation of antibiotics into the periplasm of GNB [23]. 
The effect of substituted amino functions on antibacterial activity, hemolytic activity, and enzymatic degradation in polymers and peptides have been previously studied [24-26]. It was shown that compounds containing secondary or tertiary amines were less hemolytic than their primary amino counterparts [24-26]. Likewise, alkylation of the amino groups of Lys resulted in improved resistance to proteolysis [25,26]. However, it is currently unknown how the nature of the amino function (primary, secondary, tertiary, and quaternary) in peptidic OMPs affects the permeability and potentiation of GPB-selective antibiotics in GNB. To study these effects, we prepared a series of lysine- $N-\zeta$-methylated ultrashort tetrabasic lipopeptides (UTBLPs) and studied their synergistic relationship with RIF, NOV, and NIC. Our data demonstrate that an increase in $N-\zeta$-methylation of lysine reduces the potentiating effects of UTBLPs with GPB-selective antibiotics in GNB. These results provide critical information for the design and optimization of polyamine-based OMPs.

\section{Results}

\subsection{Synthesis of UTBLPs $\mathbf{1}-\mathbf{8}$}

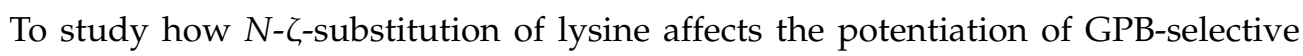
antibiotics, two classes of UTBLPs were prepared (Figure 1).<smiles>[R]C(NC(=O)CN(CCCNC(=O)C([R])NC(=O)[18F])CCCNC(=O)C([R])NC(=O)[18F])C(N)=O</smiles>

(a)

\begin{tabular}{|l|c|c|c|c|}
\hline $\mathbf{R}$ & $\mathrm{C}_{4} \mathrm{H}_{8}-\mathrm{NH}_{2}$ & $\mathrm{C}_{4} \mathrm{H}_{8}-\stackrel{\mathrm{NH}}{ }$ & $\mathrm{C}_{4} \mathrm{H}_{8}-\stackrel{\mathrm{N}}{\mid}$ & $\mathrm{C}_{4} \mathrm{H}_{8}-\stackrel{+}{\mathrm{N}-}$ \\
\hline Cmp no. & $\mathbf{1}$ & $\mathbf{2}$ & $\mathbf{3}$ & $\mathbf{4}$ \\
\hline
\end{tabular}

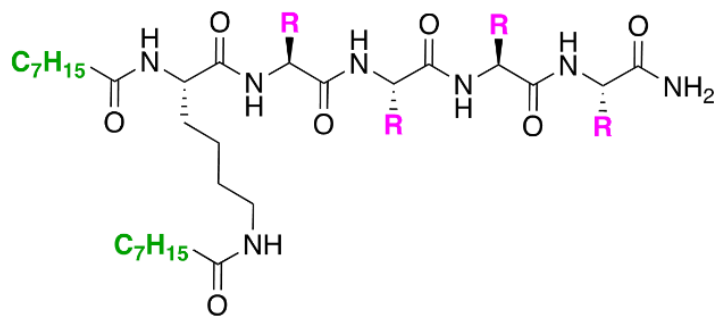

(b)

\begin{tabular}{|c|c|c|c|c|}
\hline $\mathbf{R}$ & $\mathrm{C}_{4} \mathrm{H}_{8}-\mathrm{NH}_{2}$ & $\mathrm{C}_{4} \mathrm{H}_{8}-\mathrm{NH}$ & $\mathrm{C}_{4} \mathrm{H}_{8}-\mathrm{N}$ & $\mathrm{C}_{4} \mathrm{H}_{8}-\mathrm{N}+$ \\
\hline Cmp no. & 5 & 6 & 7 & 8 \\
\hline
\end{tabular}

Figure 1. Structures of (a) branched and (b) linear UTBLPs.

Class A (compounds 1-4) consists of a branched peptide backbone, while class B (compounds 5-8) contains a linear peptide backbone. The branched peptide backbone was generated by incorporation of bis(3-aminopropyl)glycine into the growing peptide chain. Note that bis(3-aminopropyl) glycine also contains a tertiary amine, providing an additional protonizable group. Previous studies have shown that incorporation of bis(3-aminopropyl) glycine into UTBLP enhances the proteolytic stability of UTBLPs [15]. Lysine was selected as the parent amino acid due to the commercial availability of various $N$ - $\zeta$-methylated amino acid building blocks. A tetrabasic peptide scaffold containing two hydrophobic octanoyl residues was selected as this scaffold showed optimal potentiation of GPB-selective antibiotics and minimal cytotoxicity in previous studies [15]. The peptides were assembled using solid phase peptide synthesis (SPPS) on a Rink amide 4-methylbenzyhdrylamine (MBHA) resin following a fluorenylmethyloxycarbonyl (Fmoc) strategy [27].

\subsection{Antibacterial Activity of UTBLPS}

The standalone antibacterial activity of UTBLPs 1-8 was determined against a series of wild-type GNB and GPB (Table 1). 
Table 1. Antibacterial activity of UTBLPs 1-8 against wild-type GNB and wild-type GPB.

\begin{tabular}{|c|c|c|c|c|c|c|c|c|}
\hline \multirow{2}{*}{ Organism } & \multicolumn{8}{|c|}{$\operatorname{MIC}(\mu \mathrm{g} / \mathrm{mL})$} \\
\hline & 1 & 2 & 3 & 4 & 5 & 6 & 7 & 8 \\
\hline P. aeruginosa PAO1 & $>128$ & $>128$ & $>128$ & $>128$ & $>128$ & $>128$ & $>128$ & $>128$ \\
\hline A. baumannii ATCC 17978 & $>128$ & $>128$ & $>128$ & $>128$ & 64 & 64 & 128 & $>128$ \\
\hline E. coli ATCC 25922 & $>128$ & $>128$ & $>128$ & $>128$ & 64 & 32 & 64 & $>128$ \\
\hline S. aureus ATCC 29213 & 64 & 128 & $>128$ & $>128$ & 64 & 128 & $>128$ & $>128$ \\
\hline MRSA ATCC 33592 & 128 & $>128$ & $>128$ & $>128$ & 64 & $>128$ & $>128$ & $>128$ \\
\hline E. faecalis ATCC 29212 & 128 & $>128$ & $>128$ & $>128$ & 32 & 32 & 64 & 128 \\
\hline E. faecium ATCC 27270 & 64 & $>128$ & $>128$ & $>128$ & 32 & 64 & 128 & 128 \\
\hline
\end{tabular}

Our results demonstrate that UTBLPs 1-8 possess low antibacterial activity against wild-type GNB including P. aeruginosa PAO1, A. baumannii ATCC 17978, and E. coli ATCC 25922 (MIC $\geq 32 \mu \mathrm{g} / \mathrm{mL}$ ). Slightly improved antibacterial activity (MIC $\geq 16 \mu \mathrm{g} / \mathrm{mL}$ ) was seen against wild-type GPB including Staphylococcus aureus, Enterococcus faecalis, and Enterococcus faecium. Overall, the linear UTBLP $\mathbf{5}$ and $\mathbf{6}$ showed slightly improved antibacterial activity when compared to their branched counterparts 1 and $\mathbf{2}$ (Table 1). We also tested the antibacterial activity of the peptides against MDR GPB clinical isolates of Staphylococcus epidermidis and MDR GNB clinical isolates of P. aeruginosa, A. baumannii, E. coli, Enterobacter cloacae, and Klebsiella pneumoniae. Overall, these studies show that UTBLPs 1-8 display comparable MIC activities against MDR GNB (MIC $\geq 32 \mu \mathrm{g} / \mathrm{mL}$ ) and GPB (MIC $\geq 8 \mu \mathrm{g} / \mathrm{mL}$ ) when compared to wild-type organisms (Table S1).

\subsection{Synergistic Effects of UTBLPs with RIF, NOV, NIC, and CHL against GNB}

The low antibacterial activity of UTBLPs 1-8 prompted us to explore the potentiating effects of the compounds in combination with GPB-selective antibiotics against wildtype GNB. RIF and NOV were selected as examples of GPB-selective antibiotics as both antibiotics are inactive against GNB [15]. NIC was selected because it has been shown to synergize with polymyxins and overcome polymyxin resistance in polymyxin-resistant GNB [28]. Chloramphenicol (CHL) was selected as an antibiotic that is greatly affected by efflux [29]. The combination studies were performed by fixing the concentration of the UTBLPs to $6 \mu \mathrm{M}$, which is below $\frac{1}{4}$ MIC required for synergistic activity. Our results demonstrate a clear trend in the potentiating power of the various UTBLPs in combination with GPB-selective antibiotics (Figure 2). Independent of the organism and antibiotic used, the order of potentiation follows the order $1>2>3>4$ for branched peptides and $5>6>7>8$ for linear peptides for the antibiotics RIF and NOV (Figure 2a,b). A similar trend is seen for NIC except for P. aeruginosa PAO1, where no potentiation is seen for peptides 1-4 (Figure 2c). No clear trend can be observed with CHL except for P. aeruginosa PAO1 (Figure 2d). Overall, this study indicates that increasing $N-\zeta$-methylation of lysine in UTBLPs decreases the potentiation of RIF, NOV, and NIC in wild-type GNB. Next, we explored whether the effects observed in wild-type GNB can be extrapolated to clinical MDR and carbapenem-resistant GNB isolates including CRPA, CRAB, and CRE. As shown in Figure $3 \mathrm{a}, \mathrm{b}$, we were able to confirm the same trend in MDR GNB isolates as previously observed for wild-type organisms. In general, the $N$ - $\zeta$-unmethylated UTBLPs displayed higher potentiation when compared to mono- and di-methylated compounds. The lowest potentiation was consistently observed with the tri- $N-\zeta$-methylated analogs 4 and 8 . We also determined the fractional inhibitory concentration index (FICI) of compounds 1-8 with RIF, NOV, NIC, and CHL against wild-type and MDR GNB isolates (Tables S2 and S3) and the FICI with CHL against MDR GPB isolates (Table S4) to evaluate interactions between the two agents. FICI of $\leq 0.5,0.5<\mathrm{x} \leq 4$, and $>4$ were interpreted as synergy, additive, and antagonistic, respectively [30]. These results confirm that the lowest FICI (highest 
synergy) was consistently observed with unmethylated and mono-methylated UTBLPs when compared to the di- and tri-methylated analogs. None of the UTBLPs were able to synergize (FICI > 0.5) CHL against GPB (Table S4) confirming that UTBLPs act selectively on the OM of GNB. Moreover, the data in Table S4 indicate that UTBLPs 1-8 do not possess efflux pump inhibitory effects in GPB.

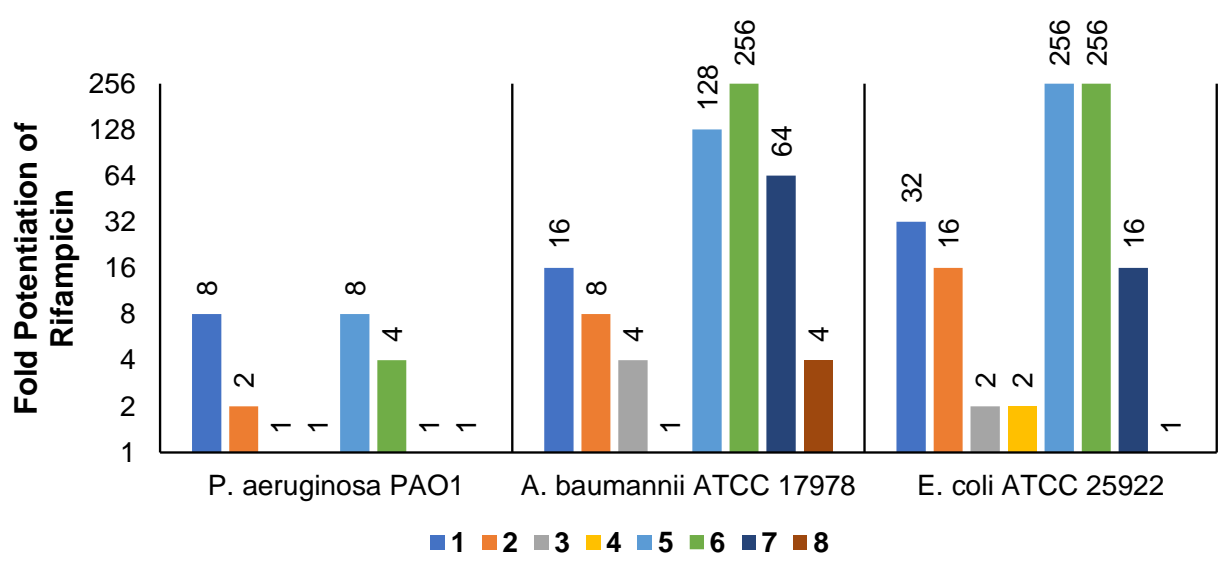

(a)

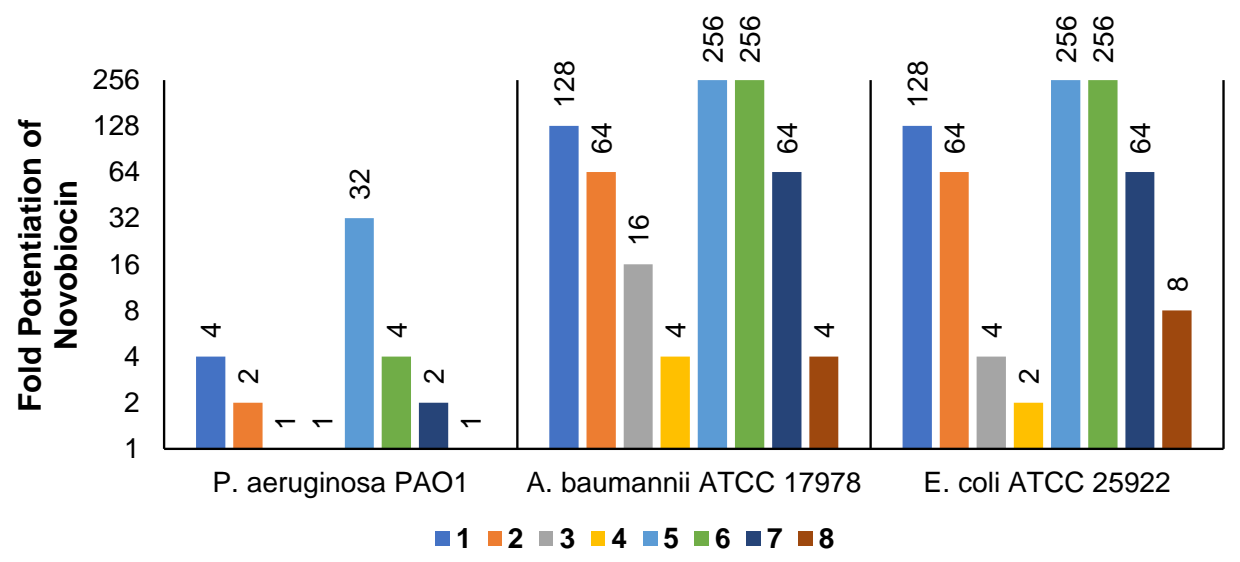

(b)

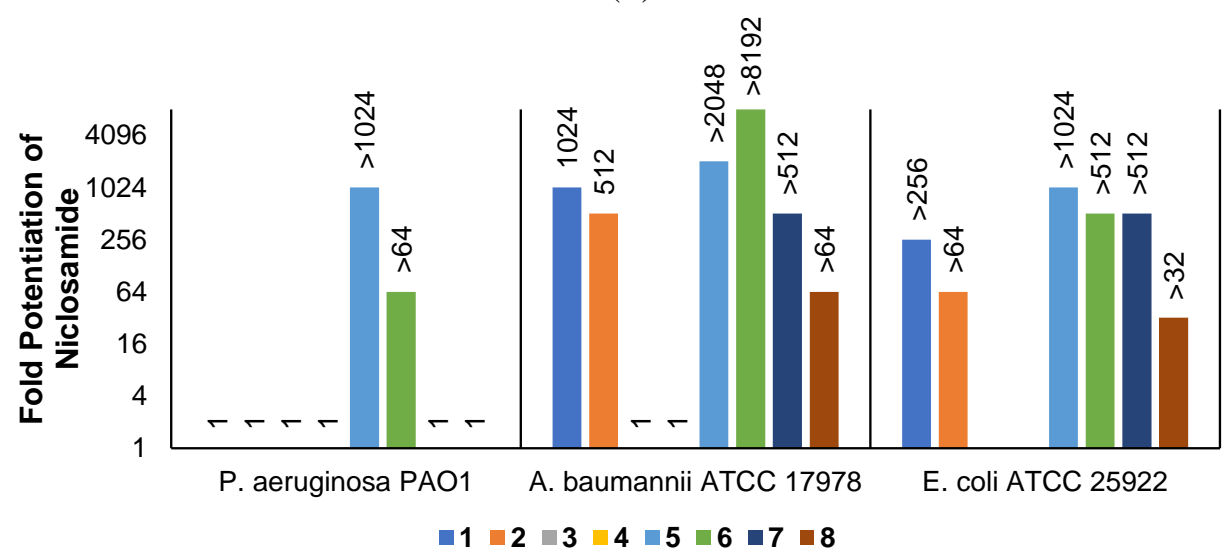

(c)

Figure 2. Cont. 


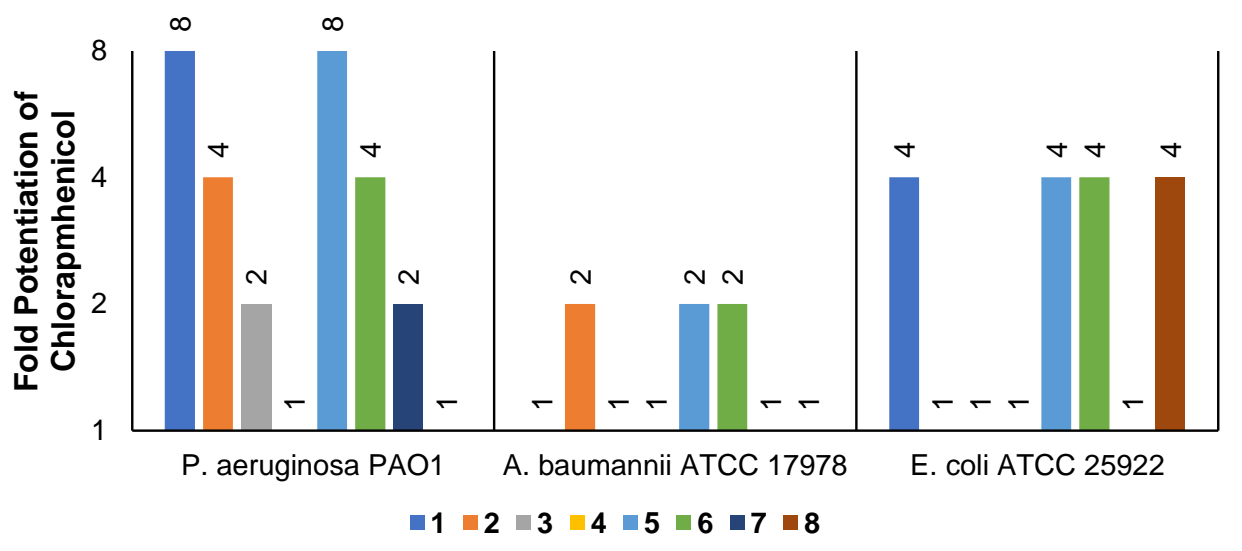

(d)

Figure 2. Potentiation of (a) RIF, (b) NOV, (c) NIC, and (d) CHL by $6 \mu$ M UTBLP against wild-type GNB.

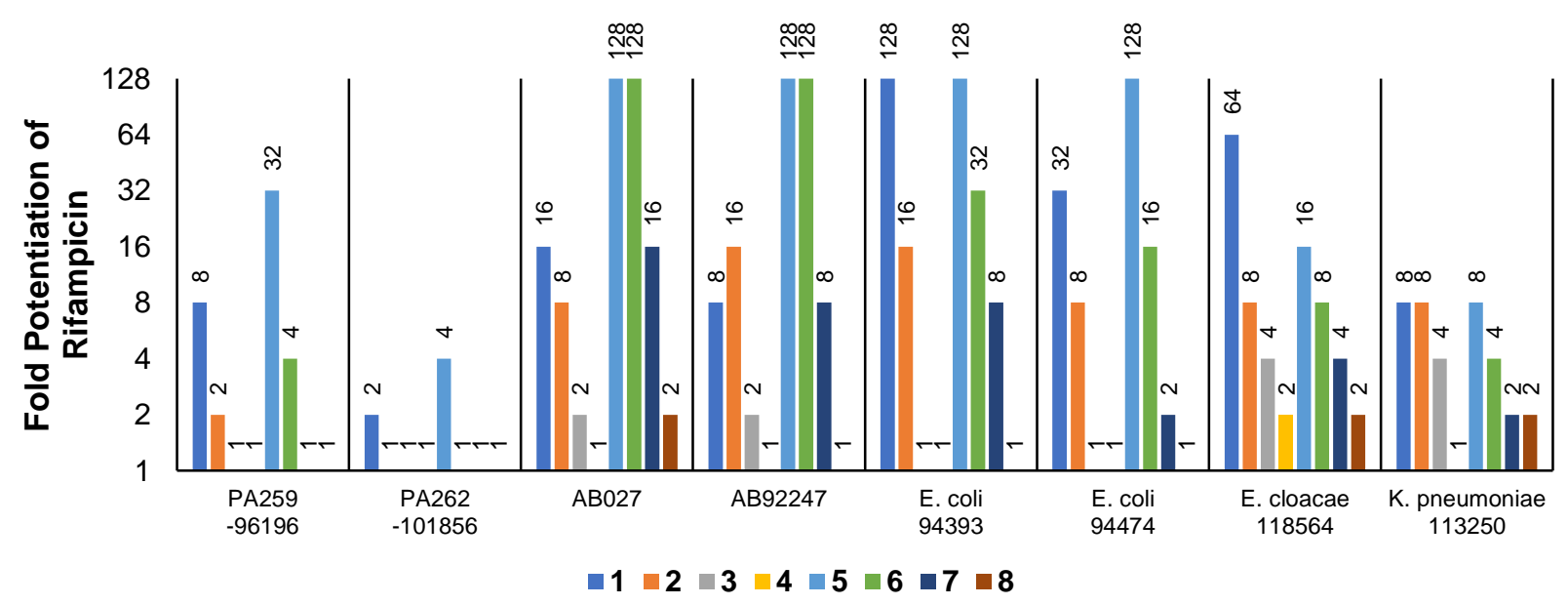

(a)

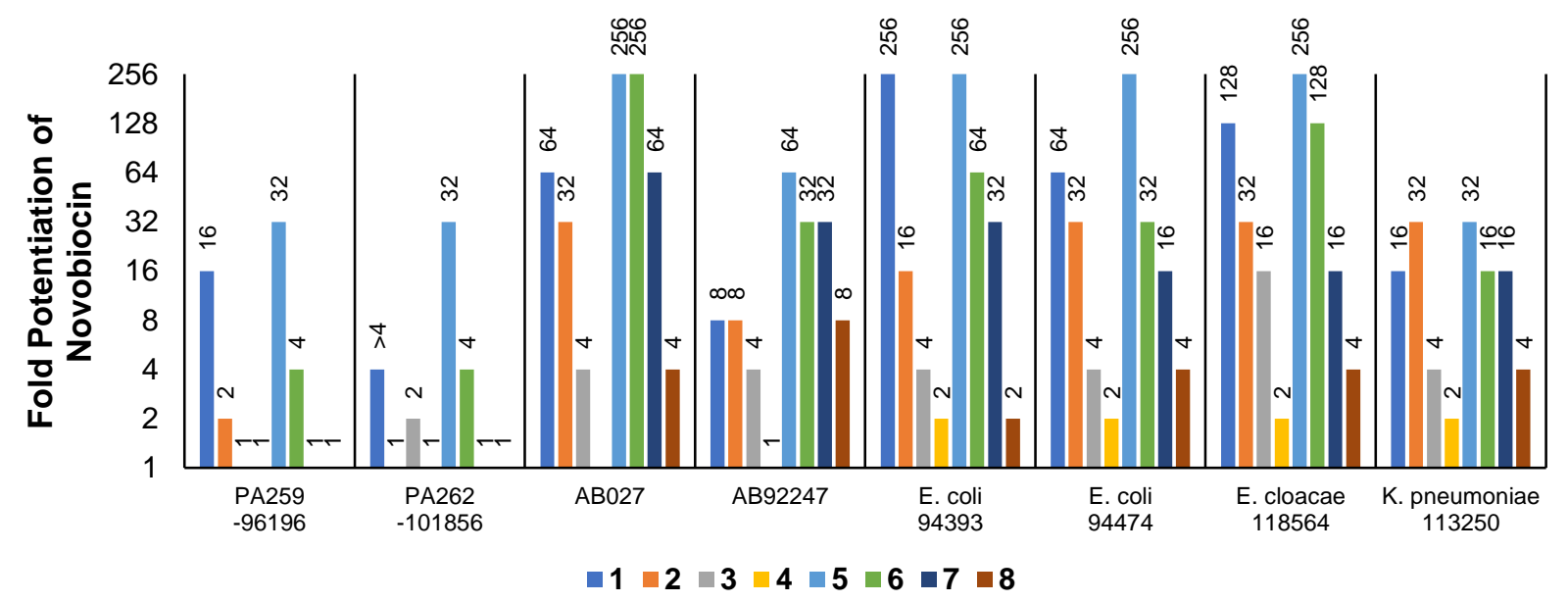

(b)

Figure 3. Potentiation of (a) RIF and (b) NOV by $6 \mu \mathrm{M}$ UTBLP against a panel of MDR and carbapenem-resistant GNB isolates. 


\subsection{Outer Membrane Permeabilization by UTBLPs 1-8}

To determine whether UTBLPs 1-8 increase the intracellular concentration of RIF, NOV, and NIC by permeabilizing the OM, the ability of the peptides to increase the uptake of the nonpolar membrane-impermeable fluorescent probe 1-N-phenylnaphthylamine (NPN) was measured in wild-type A. baumannii ATCC 17978 and E. coli ATCC 25922. NPN uptake is normally prevented when the OM is intact [14]. Moreover, NPN fluoresces strongly and weakly in phospholipid and aqueous environments, respectively [14]. For example, exposure of $A$. baumannii ATCC 17978 to various concentrations of UTBLPs 1-4 or PMBN (control) resulted in a dose-dependent increase in NPN fluorescence (Figure 4). This suggests that UTBLPs 1-4 enhance OM permeability of the probe. Comparable dosedependent increase in NPN fluorescence was observed with UTBLPs 1-4 in E. coli ATCC 25922 (Figure S1), as well as with UTBLPs 5-8 in A. baumannii ATCC 17978 (Figure S2) and E. coli ATCC 25922 (Figure S3) indicating that all UTBLPs enhance OM permeability of the probe in a dose-dependent manner. However, we were unable to correlate the antibiotic potentiation effects of UTBLPs 1-8 with RIF, NOV, and NIC to the increase in NPN fluorescence. For instance, the strongest antibiotic potentiators UTBLPs 1, 2, 5, and $\mathbf{6}$ did not consistently produce the highest NPN fluorescence at equimolar concentrations $(7 \mu \mathrm{M})$ (Figure S4). Moreover, the weakest potentiators 4 and 8, which do not or only weakly potentiate GPB-selective antibiotics, displayed comparable increases in NPN fluorescence when compared to potentiators 1, 2, 5, and 6 .

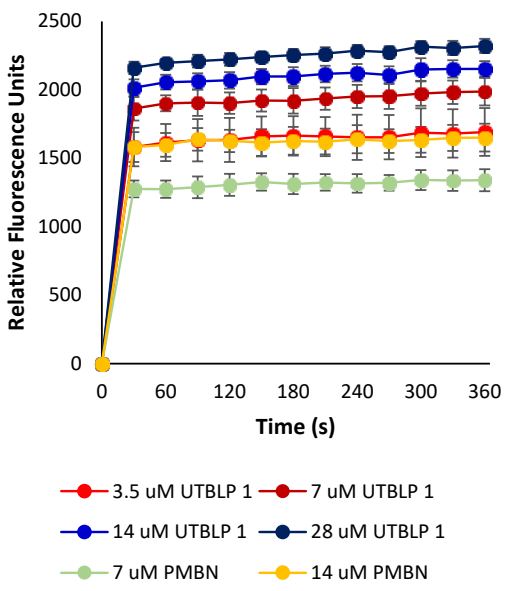

(a)

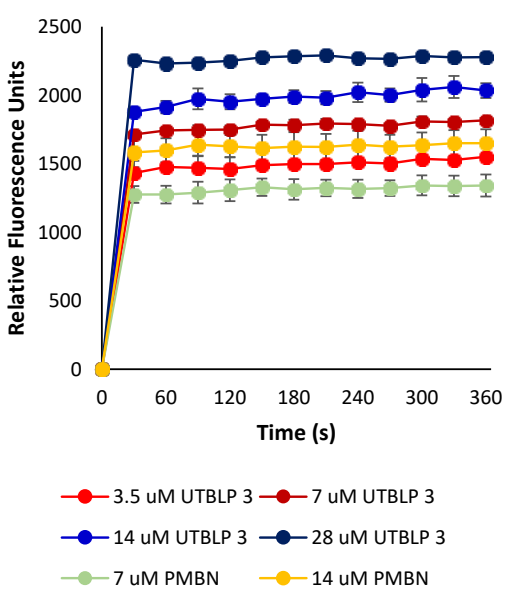

(c)

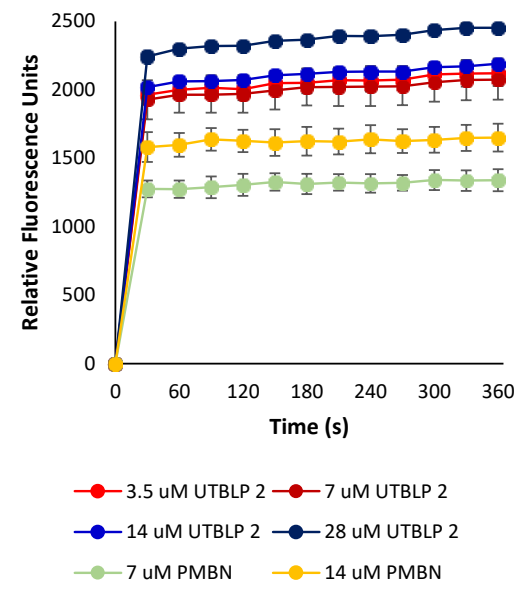

(b)

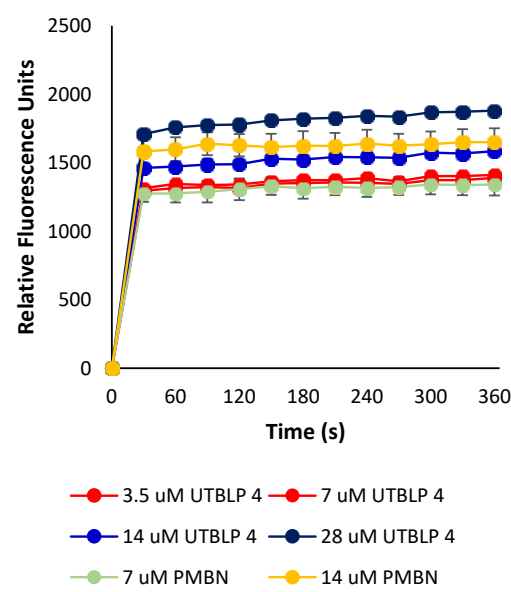

(d)

Figure 4. Dose-dependent increase in fluorescence of NPN in the presence of (a) UTBLP 1, (b) UTBLP 2, (c) UTBLP 3, (d) UTBLP 4, and PMBN (control) in A. baumannii ATCC 17978. 


\section{Discussion}

The development of OMPs to potentiate GPB-selective antibiotics against clinically relevant GNB is a promising combination strategy to overcome bacterial resistance $[6,9,10,16]$. Majority of known OMPs are polycationic amphiphiles with two or more positive charges where the cationic character is derived from protonation of amino or guanidino functions. Polyamine-based OMPs occur as antimicrobial peptides, antimicrobial peptidomimetics, aminoglycoside-based amphiphiles, cationic lipids, and detergents [6,9,10,12-16]. Polyamine-based OMPs are believed to destabilize the OM by displacing bivalent cations $\left(\mathrm{Mg}^{2+}\right.$ or $\left.\mathrm{Ca}^{2+}\right)$, which are stabilizing counterions for the phosphate groups of lipid A and the phosphorylated core sugars that prevent repulsion between and among individual LPS molecules. This leads to a localized disruption of LPS in the OM allowing non-porin mediated passage of antibiotics into the periplasm [19,23,31,32]. Prior to this study, there was no information available on how $N$-alkylation of polyamine-based OMPs affects the potentiation of GPB-selective antibiotics. We studied this effect for the first time in a systematic fashion by preparing a series of UTBLPs via incorporation of various $N-\zeta$-methylated lysine analogs into branched and linear peptide backbone scaffolds. Our results demonstrate that an increase in $N$ - $\zeta$-methylation in UTBLPs reduces the potentiation of RIF, NOV, and NIC in clinically relevant wild-type and MDR GNB. Hydrophobicity and a molecular weight above $600 \mathrm{Da}$, such as in the antibiotics RIF and NOV, reduce or prevent porin-mediated permeation through the OM. In contrast, NIC is a hydrophobic GPB-selective antibiotic with a molecular weight below 600 Da [28]. Previous studies have shown that OMPs, including PMBN and polymyxin-based antibiotics, strongly potentiate NIC against GNB indicating that the low activity of NIC against GNB is caused by low OM permeability [28]. Interestingly, none of the branched UTBLPs 1-4 potentiate NIC in P. aeruginosa PAO1. This suggests different requirements for UTBLPs to potentiate NIC against $P$. aeruginosa PAO1 when compared to other wild-type GNB. In contrast to RIF, NOV, and NIC, no potentiation trend can be observed with UTBLPs 1-8 in combination with CHL against $A$. baumannii ATCC 17978 and E. coli ATCC 25922. This likely reflects that OM permeability of CHL is less important for these organisms when compared to P. aeruginosa PAO1. The fact that CHL is potentiated in P. aeruginosa PAO1 by UTBLPs in the order $1>2>3>4$ and $5>6>7$ $>\mathbf{8}$ reflects the greatly reduced OM permeability of $P$. aeruginosa when compared to other GNB [24,25]. Moreover, we were unable to correlate the antibiotic potentiation effects of equimolar UTBLPs 1-8 with RIF, NOV, and NIC to an increase in NPN fluorescence in the OM permeability assay. This indicates that other factors besides OM permeability control the potentiation effects of RIF, NOV, and NIC in GNB. Our study shows that the nature of the peptide backbone can influence the potentiation effect of RIF, NOV, and NIC. For instance, we typically observed a two- to four-fold increase in potentiation of antibiotics in the linear UTBLPs 5-8 when compared to the branched UTBLPs 1-4. Whether the reduced potentiating effects of the branched UTBLPs 1 and 2 reflects different peptide backbone topology or reflects a reduced number of primary or secondary amino groups in UTBLPs $\mathbf{1}$ and $\mathbf{2}$ when compared to $\mathbf{5}$ and $\mathbf{6}$ needs to be further explored. In summary, our results indicate that the most effective antibiotic potentiator molecules to potentiate RIF, NOV, and NIC against GNB are UTBLPs with three or more primary amino functions.

\section{Materials and Methods}

\subsection{Materials}

The Rink amide MBHA resin, Fmoc-L-Lys(Me) ${ }_{3}-\mathrm{OH}$, and Fmoc-L-Lys(Fmoc)-OH were purchased from Sigma-Aldrich (St Louis, MO, USA). Fmoc-L-Lys(Boc)-OH was purchased from AK Scientific (Union City, CA, USA), Fmoc-L-Lys(Me,Boc)-OH from Biosynth Carbosynth (Newbury, UK), Fmoc-L-Lys(Me) $2-\mathrm{OH}$ from Bachem (Bubendorf, Switzerland), and $N, N$-bis( $\mathrm{N}^{\prime}$-Fmoc-3-aminopropyl)glycine potassium hemisulfate from Chem-Impex (Wood Dale, IL, USA). All other reagents and solvents were obtained from commercial sources and used without further purification. 


\subsection{Preparation of UTBLPS 1-8}

All UTBLPs were prepared by Fmoc SPPS [27] and as previously described [15,33]. The N-terminus of the amino acids was protected with Fmoc. The- $N$ - $\zeta$-amino function

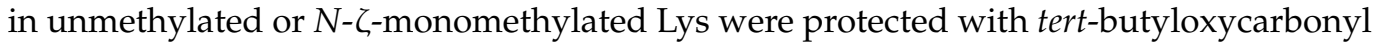
(Boc), while no side chain protecting group was necessary for $N$ - $\zeta$-dimethylated and $N$ - $\zeta$-trimethylated Lys building blocks. The Rink amide MBHA resin was loaded on the peptide synthesis vessel and was subjected to $20 \%$ piperidine to remove Fmoc. The first protected amino acid (3 mol. eq.) was mixed with $O$-(benzotriazol-1-yl)- $N, N, N^{\prime}, N^{\prime}-$ tetramethyluronium tetrafluoroborate ( 3 mol. eq.), and $N$-methylmorpholine ( 8 mol. eq.) in DMF for $5 \mathrm{~min}$. Once the Fmoc-amino acid was activated, the solution was transferred to the resin and gently agitated with nitrogen gas for $45 \mathrm{~min}$. The Fmoc removal and coupling steps were repeated for the addition of the succeeding amino acids and fatty acids. The chloranil test ( $2 \%$ chloranil in DMF) was performed on a small amount of resin to determine whether the reactions reached completion. Deprotection of sidechain protecting groups and peptide cleavage was achieved using 95\% trifluoroacetic acid (TFA) affording solid compounds as TFA salts.

The crude was purified via reverse-phase flash chromatography using a solvent system of $55 \%$ methanol spiked with $0.1 \%$ TFA. Chemical characterization and purity of the compounds were assessed with nuclear magnetic resonance (NMR) spectroscopy on a Bruker AMX-500 (Germany), and matrix-assisted laser desorption ionization mass spectrometry on a Bruker Ultraflextreme (Germany) or by electrospray ionization mass spectrometry on a Bruker Compact (Germany). The NMR spectra are provided in the Supplementary Material.

\subsubsection{Chemical Characterization of UTBLP 1}

${ }^{1} \mathrm{H}$ NMR (500 MHz, MeOD) $\delta 4.38-4.29$ (m, 1H, Lys $\left.1-\alpha\right), 4.23-4.12(\mathrm{~m}, 2 \mathrm{H}, \mathrm{Lys} 2,3-\alpha)$, 4.10-3.98 (m, 2H, Linker-1), 3.43-3.31 (m, 2H, Linker-2,4), 3.29-3.15 (m, 6H, Linker-2,4), 3.02-2.85 (m, 6H, Lys $1,2,3-\varepsilon), 2.34-2.18$ (m, 4H, Aliphatic-a), 1.99-1.88 (m, 4H, Linker-3), 1.88-1.76 (m, 3H, Lys $1,2,3-\beta), 1.76-1.63\left(\mathrm{~m}, 9 \mathrm{H}, \mathrm{Lys}_{1,2,3}-\beta+\mathrm{Lys}_{1,2,3}-\delta\right), 1.63-1.56(\mathrm{~m}, 4 \mathrm{H}$, Aliphatic-b), 1.54-1.38 (m, 6H, Lys $1,2,3-\gamma), 1.37-1.21(\mathrm{~m}, 16 \mathrm{H}$, Aliphatic-c), 0.94-0.83 (m, 6H, Aliphatic-d).

${ }^{13} \mathrm{C}$ NMR (126 MHz, MeOD) $\delta 175.25,174.67,173.89,164.82$ (carbonyl), 53.75 (Lys $\left.2,3-\alpha\right)$, 53.53 (Linker-1), $53.45\left(\right.$ Lys $\left._{1}-\alpha\right), 53.05$ (Linker-2,4), 39.01 (Lys $\left.2,3-\varepsilon\right), 38.99\left(\right.$ Lys $\left._{1}-\varepsilon\right), 35.53$ (Linker-2,4), 35.48 (Aliphatic-a), 31.47 (Aliphatic-c), 31.02, 30.78 (Lys $1,2,3-\beta+$ Lys $_{1,2,3}-\delta$ ), 28.95, 28.71 (Aliphatic-c), 26.75, 26.70 (Lys $1,2,3-\beta+$ Lys $\left._{1,2,3}-\delta\right), 25.47$ (Aliphatic-b), 23.95 (Linker-3), 22.59 (Lys $2,3-\gamma), 22.39$ (Lys $1-\gamma), 22.24$ (Aliphatic-c), 12.98 (Aliphatic-d).

MS (+TOF) $m / z$ : calculated for $\mathrm{C}_{42} \mathrm{H}_{84} \mathrm{~N}_{10} \mathrm{O}_{6}[\mathrm{M}+\mathrm{H}]^{+}$: 825.665, found: 825.766; $[\mathrm{M}+\mathrm{Na}]^{+}:$847.647, found: 847.762 .

\subsubsection{Chemical Characterization of UTBLP 2}

${ }^{1} \mathrm{H}$ NMR (500 MHz, MeOD) $\delta 4.35-4.31$ (m, 1H, Lys $\left.1-\alpha\right), 4.22-4.15\left(\mathrm{~m}, 2 \mathrm{H}, \mathrm{Lys}_{2,3}-\alpha\right)$, 4.08-3.99 (m, 2H, Linker-1), 3.48-3.31 (m, 2H, Linker-2 + Linker-4), 3.27-3.09 (m, 6H, Linker2 + Linker-4), 3.02-2.95 (m, 6H, Lys $1,2,3-\varepsilon), 2.70-2.65$ (m, 9H, methyl), 2.28-2.21 (m, 4H, Aliphatic-a), 1.91 (m, 4H, Linker-3), 1.85-1.64 (m, 12H, Lys $1,2,3-\beta+$ Lys $\left._{1,2,3}-\delta\right), 1.62-1.55$ (m, $4 \mathrm{H}$, Aliphatic-b), 1.53-1.39 (m, 6H, Lys $1,2,3-\gamma), 1.35-1.27$ (m, 16H, Aliphatic-c), 0.92-0.86 (m, $6 \mathrm{H}$, Aliphatic-d).

${ }^{13} \mathrm{C}$ NMR (126 MHz, MeOD) $\delta$ 175.24, 174.58, 173.84, 164.80 (carbonyl), 53.68 (Lys $\left.2,3-\alpha\right)$, 53.54 (Linker-1), $53.39\left(\right.$ Lys $\left._{1}-\alpha\right), 53.06$ (Linker-2,4), $48.64\left(\right.$ Lys $\left._{2,3}-\varepsilon\right), 48.60\left(\right.$ Lys $\left._{1}-\varepsilon\right), 35.53$ (Linker-2,4), 35.39 (Aliphatic-a), 32.12 (methyl), 31.47 (Aliphatic-c), 31.03, 30.77 (Lys $1,2,3-\beta+$ Lys $_{1,2,3}-\delta$ ), 28.96, 28.72 (Aliphatic-c), 25.48 (Aliphatic-b), 25.32, 25.26 (Lys $1,2,3-\beta+$ Lys $_{1,2,3}-\delta$ ), 23.96 (Linker-3), 22.59 (Lys $2,3-\gamma), 22.39\left(\mathrm{Lys}_{1}-\gamma\right), 22.24$ (Aliphatic-c), 12.98 (Aliphatic-d).

MS (+TOF) $m / z$ : calculated for $\mathrm{C}_{45} \mathrm{H}_{90} \mathrm{~N}_{10} \mathrm{O}_{6}[\mathrm{M}+\mathrm{H}]^{+}:$867.712, found: 867.800; $[\mathrm{M}+\mathrm{Na}]^{+}:$889.694, found: $889.797 ;[\mathrm{M}+\mathrm{K}]^{+}:$905.803, found: 905.793. 


\subsubsection{Chemical Characterization of UTBLP 3}

${ }^{1} \mathrm{H}$ NMR (500 MHz, MeOD) $\delta ~ 4.36-4.31 ~\left(m, 1 H\right.$, Lys $\left._{1}-\alpha\right), 4.23-4.16\left(\mathrm{~m}, 2 \mathrm{H}, \mathrm{Lys}_{2,3}-\alpha\right)$, 4.12-3.94 (m, 2H, Linker-1), 3.38-3.30 (m, 2H, Linker-2 + Linker-4), 3.29-3.16 (m, 6H, Linker2 + Linker-4), 3.15-3.08 (m, 6H, Lys $1,2,3-\varepsilon), 2.88-2.85$ (m, 18H, methyl), 2.31-2.22 (m, 4H, Aliphatic-a), 1.96-1.88 (m, 4H, Linker-3), 1.87-1.65 (m, 12H, Lys $1,2,3-\beta+$ Lys $\left._{1,2,3}-\delta\right), 1.63-1.56$ (m, 4H, Aliphatic-b), 1.52-1.38 (m, 6H, Lys $1,2,3-\gamma), 1.35-1.25(\mathrm{~m}, 16 \mathrm{H}$, Aliphatic-c), 0.96-0.84 (m, 6H, Aliphatic-d).

${ }^{13} \mathrm{C}$ NMR (126 MHz, MeOD) $\delta$ 175.22, 174.58, 173.79, 164.80 (carbonyl), 57.24 (Lys 2,3 $\varepsilon), 57.20\left(\right.$ Lys $\left._{1}-\varepsilon\right), 53.61\left(\right.$ Lys $\left._{2,3}-\alpha\right), 53.54$ (Linker-1), 53.37 (Lys $\left.1-\alpha\right), 53.08$ (Linker-2,4), 41.97 (methyl), 35.54 (Linker-2,4), 35.40 (Aliphatic-a), 31.47 (Aliphatic-c), 31.01, 30.76 (Lys $1,2,3-\beta+$ Lys $_{1,2,3}-\delta$ ), 28.97, 28.72 (Aliphatic-c), 25.48 (Aliphatic-b), 23.94 (Linker-3), 23.72, 23.63 (Lys $1,2,3-\beta$ + $\left.\mathrm{Lys}_{1,2,3}-\delta\right), 22.53\left(\mathrm{Lys}_{2,3}-\gamma\right), 22.35\left(\mathrm{Lys}_{1}-\gamma\right), 22.24$ (Aliphatic-c), 12.98 (Aliphatic-d).

MS (+TOF) $m / z$ : calculated for $\mathrm{C}_{48} \mathrm{H}_{96} \mathrm{~N}_{10} \mathrm{O}_{6}[\mathrm{M}+\mathrm{H}]^{+}$: 909.759, found: 909.849 ; $[\mathrm{M}+\mathrm{Na}]^{+}:$931.503, found: $931.837 ;[\mathrm{M}+\mathrm{K}]^{+}:$947.850, found: 947.809.

\subsubsection{Chemical Characterization of UTBLP 4}

${ }^{1} \mathrm{H}$ NMR (500 MHz, MeOD) $\delta$ 4.36-4.32 (m, 1H, Lys $\left.1-\alpha\right), 4.23-4.16$ (m, 2H, Lys $2,3^{-}$

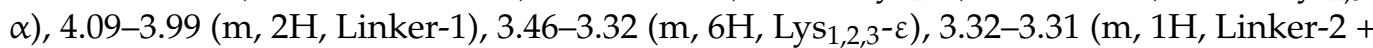
Linker-4), 3.29-3.19 (m, 7H, Linker-2 + Linker-4), 3.15-3.08 (m, 27H, methyl), 2.30-2.21 (m, 4H, Aliphatic-a), 1.96-1.90 (m, 4H, Linker-3), 1.89-1.67 (m, 12H, Lys 1,2,3- $\beta+$ Lys $_{1,2,3}-\delta$ ), 1.64-1.56 (m, 4H, Aliphatic-b), 1.51-1.37 (m, 6H, Lys $1,2,3-\gamma)$, 1.35-1.25 (m, 16H, Aliphatic-c), 0.93-0.84 (m, 6H, Aliphatic-d).

${ }^{13} \mathrm{C}$ NMR (126 MHz, MeOD) $\delta 175.21,174.48,173.72,164.80$ (carbonyl), 66.06 (Lys 2,3 $\varepsilon), 66.01\left(\mathrm{Lys}_{1}-\varepsilon\right), 53.58\left(\mathrm{Lys}_{2,3}-\alpha\right), 53.51$ (Linker-1), $53.39\left(\mathrm{Lys}_{1}-\alpha\right), 53.10$ (Linker-2,4), 52.13 (methyl), 52.11 (methyl), 52.07 (methyl), 35.56 (Linker-2,4), 35.42 (Aliphatic-a), 31.48 (Aliphatic-c), 31.07, 30.79 (Lys $1,2,3-\beta+$ Lys $_{1,2,3}-\delta$ ), 28.98, 28.73 (Aliphatic-c), 25.50 (Aliphaticb), 23.96 (Linker-3), 22.44, $22.25\left(\right.$ Lys $_{1,2,3}-\beta+$ Lys $\left._{1,2,3}-\delta\right), 22.18\left(\right.$ Lys $\left._{2,3}-\gamma\right), 22.13$ (Lys $\left.1-\gamma\right), 22.07$ (Aliphatic-c), 12.98 (Aliphatic-d).

MS (+TOF) $m / z$ : calculated for $\mathrm{C}_{51} \mathrm{H}_{105} \mathrm{~N}_{10} \mathrm{O}_{6}{ }^{3+}[\mathrm{M}+\mathrm{TFA}]^{2+}: 533.403$, found: 533.398 .

\subsubsection{Chemical Characterization of UTBLP 5}

${ }^{1} \mathrm{H}$ NMR (500 MHz, MeOD) $\delta 4.34-4.24$ (m, 4H, Lys $\left.1,2,3,4-\alpha\right), 4.17-4.12$ (m, 1H, Lys $\left.5-\alpha\right)$, 3.17-3.12 (m, 2H, Lys $5-\varepsilon), 2.98-2.89\left(\mathrm{~m}, 8 \mathrm{H}, \mathrm{Lys}_{1,2,3,4}-\varepsilon\right), 2.29-2.21$ (m, 2H, Aliphatic 1 -a), 2.16 (m, 2H, Aliphatic 2 -a), 1.90-1.81 (m, 4H, Lys $2,3,4,5-\beta), 1.79-1.72\left(\mathrm{~m}, 4 \mathrm{H}, \mathrm{Lys}_{2,3,4,5}-\beta\right)$, 1.71-1.62 (m, 10H, Lys $1-\beta+$ Lys $\left._{1,2,3,4}-\delta\right), 1.62-1.55$ (m, 4H, Aliphatic $\left.1,2-b\right), 1.54-1.35$ (m, 12H, Lys $_{1,2,3,4,5}-\gamma+$ Lys $\left._{5}-\delta\right), 1.34-1.25(\mathrm{~m}, 16 \mathrm{H}$, Aliphatic $1,2-\mathrm{c}), 0.93-0.85$ (m, 6H, Aliphatic $\left.1,2-\mathrm{d}\right)$.

${ }^{13} \mathrm{C}$ NMR (126 MHz, MeOD) $\delta 175.48,175.12,174.92,173.84,172.96,172.91,172.58$ (carbonyl), 54.22 (Lys5- $\alpha), 53.47,53.42,53.37,52.78\left(\right.$ Lys $\left._{1,2,3,4}-\alpha\right), 39.17,39.12,39.07,39.02$ $\left(\right.$ Lys $_{1,2,3,4}-\varepsilon$ ), 38.51 (Lys $5-\varepsilon$ ), 35.77 (Aliphatic 2 -a), 35.31 (Aliphatic 1 -a), 31.48, 31.45 (Aliphatic $1,2^{-}$ c), 31.07, 30.70, 30.68, 30.65, $30.42\left(\right.$ Lys $\left._{1,2,3,4,5-\beta}\right), 28.92,28.87,28.71,28.69,28.65\left(\mathrm{Lys}_{5}-\delta+4\right.$

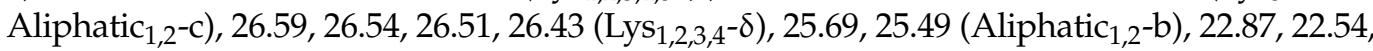
22.41, 22.32, 22.30, 22.23, 22.22 (Lys $1,2,3,4,5-\gamma+2$ Aliphatic-c), 12.98, 12.97 (Aliphatic $1,2-\mathrm{d}$ ).

MS (+TOF) $m / z$ : calculated for $\mathrm{C}_{46} \mathrm{H}_{91} \mathrm{~N}_{11} \mathrm{O}_{7}[\mathrm{M}+\mathrm{H}]^{+}$: 910.718, found: 910.718; $[\mathrm{M}+\mathrm{Na}]^{+}:$933.700, found: $932.700 ;[\mathrm{M}+2 \mathrm{H}]^{2+}: 455.862$, found: 455.867 .

\subsubsection{Chemical Characterization of UTBLP 6}

${ }^{1} \mathrm{H}$ NMR (500 MHz, MeOD) $\delta$ 4.35-4.20 (m, 4H, Lys $\left.1,2,3,4-\alpha\right), 4.18-4.12$ (m, 1H, Lys $\left.5-\alpha\right)$, 3.18-3.11 (m, 2H, Lys $5-\varepsilon), 3.07-2.88$ (m, 8H, Lys $1,2,3,4-\varepsilon), 2.81-2.55$ (m, 12H, methyl), 2.302.20 (m, 2H, Aliphatic $\left.{ }_{1}-\mathrm{a}\right), 2.19-2.13$ (m, 2H, Aliphatic $\left.2-\mathrm{a}\right), 1.95-1.82$ (m, 4H, Lys $\left.2,3,4,5-\beta\right)$, 1.82-1.73 (m, 4H, Lys $2,3,4,5-\beta), 1.73-1.64\left(\mathrm{~m}, 10 \mathrm{H}, \mathrm{Lys}_{1}-\beta+\mathrm{Lys}_{1,2,3,4}-\delta\right), 1.62-1.55(\mathrm{~m}, 4 \mathrm{H}$, Aliphatic $\left._{1,2}-\mathrm{b}\right), 1.55-1.35$ (m, 12H, Lys $1,2,3,4,5-\gamma+$ Lys $\left._{5}-\delta\right), 1.35-1.22$ (m, 16H, Aliphatic $\left.1,2-\mathrm{c}\right)$, 0.99-0.75 (m, 6H, Aliphatic $1,2-\mathrm{d})$.

${ }^{13} \mathrm{C}$ NMR (126 MHz, MeOD) $\delta 175.38,175.05,174.89,173.73,172.83,172.77,172.51$ (carbonyl), 54.12 (Lys $\left.{ }^{-} \alpha\right), 53.25,53.23,53.20,52.77\left(\right.$ Lys $\left._{1,2,3,4}-\alpha\right), 48.69,48.66,48.64,48.59$ 
$\left(\right.$ Lys $\left._{1,2,3,4}-\varepsilon\right), 38.51$ (Lys $\left.5-\varepsilon\right), 35.78$ (Aliphatic 2 -a), 35.34 (Aliphatic 1 -a), 32.21, 32.19, 32.17, 32.15 (methyl), 31.48, 31.46 (Aliphatic 1,2 -c), 31.09, 30.75, 30.70, 30.48, 30.31, 28.93, 28.88, 28.73, 28.70 (Lys $_{1,2,3,4,5} \beta+4$ Aliphatic $\left._{1,2}-\mathrm{c}\right), 25.70,25.57,25.53,25.49,25.16,25.12,25.09$ $\left(\right.$ Lys $_{1,2,3,4,5}-\delta+2$ Aliphatic $\left._{1,2}-\mathrm{b}\right), 22.89,22.49,22.41,22.37,22.29,22.24,22.23$ (Lys $_{1,2,3,4,5^{-}} \gamma+$ 2 Aliphatic $1,2-\mathrm{c}), 12.98,12.97$ (Aliphatic $1,2-\mathrm{d}$ ).

MS (+TOF) $m / z$ : calculated for $\mathrm{C}_{50} \mathrm{H}_{99} \mathrm{~N}_{11} \mathrm{O}_{7}[\mathrm{M}+\mathrm{H}]^{+}$: 966.780, found: 966.781; $[\mathrm{M}+2 \mathrm{H}]^{2+}: 483.894$, found: 483.897 .

\subsubsection{Chemical Characterization of UTBLP 7}

${ }^{1} \mathrm{H}$ NMR (500 MHz, MeOD) $\delta 4.33-4.25$ (m, 4H, Lys 1,2,3,4- $\alpha$ ), 4.19-4.13 (m, 1H, Lys $\left.5-\alpha\right)$, 3.16-3.09 (m, 10H, Lys $1,2,3,4,5-\varepsilon), 2.88-2.86$ (m, 24H, methyl), 2.30-2.22 (m, 2H, Aliphatic 1 -a), 2.19-2.14 (m, 2H, Aliphatic $2-a), 1.91-1.84\left(\mathrm{~m}, 4 \mathrm{H}, \mathrm{Lys}_{2,3,4,5}-\beta\right), 1.82-1.76\left(\mathrm{~m}, 4 \mathrm{H}, \mathrm{Lys}_{2,3,4,5}-\beta\right)$, 1.75-1.64 (m, 10H, Lys $1-\beta+$ Lys $\left._{1,2,3,4}-\delta\right), 1.62-1.56(\mathrm{~m}, 4 \mathrm{H}$, Aliphatic $1,2-\mathrm{b}), 1.53-1.39$ (m, 12H, Lys $_{1,2,3,4,5-\gamma}+$ Lys $\left._{5}-\delta\right), 1.34-1.27$ (m, 16H, Aliphatic $\left.1,2-\mathrm{c}\right), 0.91-0.87$ (m, 6H, Aliphatic $\left.1,2-\mathrm{d}\right)$.

${ }^{13} \mathrm{C}$ NMR (126 MHz, MeOD) $\delta$ 175.31, 174.97, 174.87, 173.66, 172.76, 172.68, 172.44 (carbonyl), 57.37, 57.35, 57.27, $57.17\left(\right.$ Lys $\left._{1,2,3,4}-\varepsilon\right), 57.16$ (Lys $\left.{ }^{-\alpha}\right), 54.04,53.14,53.11,52.73$ $\left(\right.$ Lys $_{1,2,3,4}-\alpha$ ), 42.15, 42.12, 42.03, 41.99, 41.90, 41.88, 41.84, 41.81, 38.52 (Lys $5^{-\varepsilon}$ ), 35.79 (Aliphatic ${ }^{-}$ a), 35.38 (Aliphatic 1 -a), 31.48, 31.46, 31.12, 30.85, 30.81, 30.76, 30.56, 28.94, 28.88, 28.74, 28.70

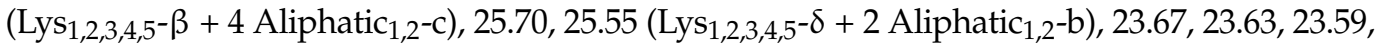
23.57, 23.53, 22.92, 22.40, 22.36, 22.33, 22.25, 22.23, 22.21 ( $\operatorname{Lys}_{1,2,3,4,5}-\gamma+2$ Aliphatic $\left.1,2-\mathrm{c}\right), 12.99$, 12.97 (Aliphatic $1,2-\mathrm{d}$ ).

MS (+TOF) $m / z$ : calculated for $\mathrm{C}_{54} \mathrm{H}_{107} \mathrm{~N}_{11} \mathrm{O}_{7}[\mathrm{M}+\mathrm{H}]^{+}:$1022.843, found: 1022.828 ; $[\mathrm{M}+\mathrm{Na}]^{+}:$1044.825, found: $1044.810 ;[\mathrm{M}+2 \mathrm{H}]^{2+}: 511.925$, found: $511.919 ;[\mathrm{M}+2 \mathrm{Na}]^{2+}$ : 533.908, found: 533.397.

\subsubsection{Chemical characterization of UTBLP 8}

${ }^{1} \mathrm{H}$ NMR (500 MHz, MeOD) $\delta 4.38-4.28$ (m, 4H, Lys $\left.1,2,3,4-\alpha\right), 4.21-4.15$ (m, 1H, Lys $\left.5-\alpha\right)$, 3.38-3.30 (m, 8H, Lys $1,2,3,4-\varepsilon), 3.18-3.15$ (m, 2H, Lys 5 - $)$, 3.14-3.05 (m, 36H, methyl), 2.31-2.20 (m, 2H, Aliphatic $1-a), 2.19-2.13$ (m, 2H, Aliphatic $2-a), 1.97-1.87$ (m, 4H, Lys 2,3,4,5- $\beta$ ), 1.87-1.82 (m, 4H, Lys $2,3,4,5-\beta), 1.81-1.67$ (m, 10H, Lys $1-\beta+$ Lys $\left._{1,2,3,4}-\delta\right), 1.62-1.55$ (m, 4H, Aliphatic $\left.1,2-b\right)$, 1.54-1.37 (m, 12H, Lys $1,2,3,4,5-\gamma+$ Lys $\left._{5}-\delta\right), 1.34-1.24$ (m, 16H, Aliphatic $\left.1,2-\mathrm{c}\right), 0.94-0.82$ (m, 6H, Aliphatic $1,2-\mathrm{d})$.

${ }^{13} \mathrm{C}$ NMR (126 MHz, MeOD) $\delta 175.23,174.89,174.85,173.61,172.69,172.62,172.39$ (carbonyl), 66.20, 66.13, 66.12, 66.02 (Lys $1,2,3,4-\varepsilon), 53.97$ (Lys $5-\alpha), 53.16,53.07,53.04,52.69$ (Lys $_{1,2,3,4}-\alpha$ ), 52.15 (methyl), 38.53 (Lys $5-\varepsilon$ ), 35.79 (Aliphatic 2 -a), 35.41 (Aliphatic 1 -a), 31.48, 31.45, 31.17, 30.90, 30.81, 30.77, 30.61, 28.94, 28.88, 28.73, 28.69 (Lys $_{1,2,3,4,5-\beta}+4$ Aliphatic $1,2^{-}$ c), 25.71, $25.56\left(\right.$ Lys $_{1,2,3,4,5}-\delta+2$ Aliphatic $\left._{1,2}-\mathrm{b}\right), 23.01,22.94,22.38,22.30,22.24,22.22,22.13$, 21.99, 21.95, 21.93, 21.91, 21.84 ( Lys $_{1,2,3,4,5}-\gamma+2$ Aliphatic $\left._{1,2}-\mathrm{c}\right), 12.98,12.97$ (Aliphatic 1,2 -d).

MS (+TOF) $m / z$ : calculated for $\mathrm{C}_{58} \mathrm{H}_{119} \mathrm{~N}_{11} \mathrm{O}_{7}{ }^{4+}[\mathrm{M}+2 \mathrm{TFA}]^{2+}: 653.949$, found: 653.942 .

\subsection{Bacterial Strains}

Bacterial strains from the American Type Culture Collection (ATCC) include A. baumannii ATCC 17978, E. coli ATCC 25922, Staphylococcus aureus ATCC 29213, methicillin-resistant S. aureus (MRSA) ATCC 33592, Enterococcus faecalis ATCC 29212, and Enterococcus faecium ATCC. Methicillin-resistant Staphylococcus epidermidis (MRSE) 61589 was acquired from the Canadian National Intensive Care Unit (CAN-ICU) surveillance study [34]. Clinical isolates A. baumannii AB027, E. coli 94393, E. coli 94474, and methicillin-susceptible Staphylococcus epidermidis (MSSE) 81388 were obtained from the Canadian Ward (CAN-WARD) surveillance study [35].

\subsection{Antimicrobial Susceptibility Assay}

The in vitro antibacterial activity of the UTBLPs was assessed against wild-type and clinically isolated bacterial strains. To obtain the MIC of the compounds, the microbroth dilution susceptibility assay was performed according to the Clinical and Laboratory Stan- 
dards Institute (CLSI, Wayne, PA, USA) guidelines [36] and as previously described [15,33]. Briefly, the compounds at varying concentrations were incubated with bacterial inoculum $\left(5 \times 10^{5} \mathrm{CFU} / \mathrm{mL}\right.$ final concentration) at $37^{\circ} \mathrm{C}$ for $18 \mathrm{~h}$. Growth in the form of turbidity was confirmed using an EMax Plus microplate reader (Molecular Devices, San Jose, CA, USA) at $590 \mathrm{~nm}$.

\subsection{Checkerboard Assay}

The synergy of the UTBLPs with various antibiotics was assessed using checkerboard assay as previously described $[15,33]$. Briefly, the combination of antibiotic and OMP at varying concentrations were incubated with bacterial inoculum $\left(5 \times 10^{5} \mathrm{CFU} / \mathrm{mL}\right.$ final concentration) at $37^{\circ} \mathrm{C}$ for $18 \mathrm{~h}$. Growth in the form of turbidity was confirmed using an EMax Plus microplate reader (Molecular Devices, Union City, CA, USA) at 590 nm. Fractional inhibitory concentration index (FICI) was used to evaluate the interaction between the antibiotic and the OMP. FICI is the sum of the FIC of the antibiotic and the FIC of the OMP. The FIC value is calculated by dividing the MIC of the agents in combination by the MIC of the agent alone. FICI $\leq 0.5$ is synergistic, $0.5<x \leq 4$ is additive, and $>4$ is antagonistic [30].

\subsection{OM Permeabilization Assay}

The ability of UTBLPs to permeabilize the OM was assessed using NPN as previously described with minor modifications [13,15,33,37]. In brief, NPN (10 $\mu \mathrm{M}$ final concentration) was incubated with the cell suspension $\left(\mathrm{OD}_{600}=0.4-0.6\right)$ in buffer $(5 \mathrm{mM}$ HEPES, $5 \mathrm{mM}$ glucose, $5 \mu \mathrm{M}$ carbonyl cyanide 3-chlorophenylhydrazone, $\mathrm{pH}$ 7.2) at room temperature for 30 min in darkness. Varying concentrations of compound diluted in the same buffer were subsequently added to the plate, and the fluorescence $\left(\lambda_{\mathrm{Ex}}=350 \mathrm{~nm}, \lambda_{\mathrm{Em}}=420 \mathrm{~nm}\right)$ was monitored every $30 \mathrm{~s}$ on a SpectraMax M2 microplate reader (Molecular Devices, Union City, CA, USA). Measurements were done in triplicates.

\section{Conclusions}

This study demonstrates that an increase in $N-\zeta$-methylation of lysine in UTBLPS reduces or abolishes the potentiating effects in these compounds to synergize with OMimpermeable antibiotics like rifampicin, novobiocin, and niclosamide. Our structureactivity relationship results are of interest for the optimization of OMPs that are currently undergoing clinical and preclinical testing as well as for the design of the next generation of OMPs. It is expected that our results can be applied to other classes of related polybasic OMPs including antimicrobial peptides, antimicrobial peptidomimetics, amphiphilic aminoglycosides, and cationic lipids.

Supplementary Materials: The following supporting information can be downloaded at: https:/ / www.mdpi.com/article/10.3390/antibiotics11030335/s1, Table S1: Antibacterial activity of UTBLPs 1-8 against MDR GNB and clinically relevant GPB. Table S2: Synergy evaluation of UTBLPs 1-8 combined with RIF, NOV, NIC, or CHL against wild-type GNB; Table S3: Synergy evaluation of UTBLPs 1-8 combined with RIF or NOV against MDR GNB; Table S4: Synergy evaluation of UTBLPs 1-8 combined with CHL against GPB; Figure S1: Dose-dependent increase in fluorescence of NPN in the presence of (A) UTBLP 1, (B) UTBLP 2, (C) UTBLP 3, (D) UTBLP 4, and PMBN (control) in E. coli ATCC 25922; Figure S2: Dose-dependent increase in fluorescence of NPN in the presence of (A) UTBLP 5, (B) UTBLP 6, (C) UTBLP 7, (D) UTBLP 8, and PMBN (control) in A. baumannii ATCC 17978; Figure S3: Dose-dependent increase in fluorescence of NPN in the presence of (A) UTBLP 5, (B) UTBLP 6, (C) UTBLP 7, (D) UTBLP 8, and PMBN (control) in E. coli ATCC 25922; Figure S4: Comparison of UTBLP-induced fluorescence of NPN at $7 \mu \mathrm{M}$ of (A) UTBLPs 1-4 and (B) UTBLPs 5-8 in A. baumannii ATCC 17978, and $7 \mu \mathrm{M}$ of (C) UTBLPs 1-4 and (D) UTBLPs 5-8 in E. coli ATCC 25922; NMR spectra $\left({ }^{1} \mathrm{H},{ }^{13} \mathrm{C}\right.$, COSY, HSQC and HMBC) of UTBLPs 1-8; Table S5: MICs (in $\left.\mu \mathrm{g} / \mathrm{mL}\right)$ of various antibiotics against MDR GNB used in the study.

Author Contributions: Conceptualization, L.S., D.R. and F.S.; Validation, L.S. and D.R.; Formal analysis, L.S. and D.R.; Investigation, L.S. and D.R.; Resources, F.S.; Writing-original draft preparation, 
L.S., D.R. and F.S.; Writing-review and editing, L.S., D.R. and F.S.; Visualization, L.S., D.R. and F.S.; Supervision, D.R. and F.S.; Project administration, L.S., D.R. and F.S.; Funding acquisition, F.S. All authors have read and agreed to the published version of the manuscript.

Funding: This research was funded by the Canadian Institutes of Health Research (CIHR) in the form of a pilot project (162159) and the Natural Sciences and Engineering Research Council of Canada (NSERC) in the form of a discovery grant (2018-06047).

Data Availability Statement: The data presented in this study are available within the article and the Supplementary Material.

Acknowledgments: We thank A. Kumar and Y. Li for their assistance on the outer membrane permeabilization assay, and the use of their microplate reader.

Conflicts of Interest: The authors declare no conflict of interest.

\section{References}

1. Ferri, M.; Ranucci, E.; Romagnoli, P.; Giaccone, V. Antimicrobial resistance: A global emerging threat to public health systems. Crit. Rev. Food Sci. Nutr. 2017, 57, 2857-2876. [CrossRef] [PubMed]

2. Mulani, M.S.; Kamble, E.E.; Kumkar, S.N.; Tawre, M.S.; Pardesi, K.R. Emerging Strategies to Combat ESKAPE Pathogens in the Era of Antimicrobial Resistance: A Review. Front. Microbiol. 2019, 10, 539. [CrossRef] [PubMed]

3. Mancuso, G.; Midiri, A.; Gerace, E.; Biondo, C. Bacterial Antibiotic Resistance: The Most Critical Pathogens. Pathogens 2021, 10, 1310. [CrossRef] [PubMed]

4. Antibiotics Currently in Global Clinical Development. Available online: https://www.pewtrusts.org/en/research-and-analysis/ data-visualizations / 2014/antibiotics-currently-in-clinical-development (accessed on 18 January 2022).

5. O'Neill, J. Tackling Drug-Resistant Infections Globally: Final Report and Recommendations; Review on Antimicrobial Resistance: London, UK, 2016.

6. Domalaon, R.; Idowu, T.; Zhanel, G.G.; Schweizer, F. Antibiotic hybrids: The next generation of agents and adjuvants against Gram-negative pathogens? Clin. Microbiol. Rev. 2018, 31, e02374-17. [CrossRef] [PubMed]

7. Brown, D.G.; May-Dracka, T.L.; Gagnon, M.M.; Tommasi, R. Trends and exceptions of physical properties on antibacterial activity for Gram-positive and Gran-negative pathogens. J. Med. Chem. 2014, 57, 10144-10161. [CrossRef]

8. Richter, M.F.; Drown, B.S.; Riley, A.P.; Garcia, A.; Shirai, T.; Svec, R.L.; Hergenrother, P.J. Predictive compound accumulation rules yield a broad-spectrum antibiotic. Nature 2017, 545, 299-304. [CrossRef]

9. Vaara, M. Agents that increase the permeability of the outer membrane. Microbiol. Rev. 1992, 56, 395-411. [CrossRef]

10. Corbett, D.; Wise, A.; Langley, T.; Skinner, K.; Trimby, E.; Birchall, S.; Dorali, A.; Sandiford, S.; Williams, J.; Warn, P.; et al Potentiation of Antibiotic Activity by a Novel Cationic Peptide: Potency and Spectrum of Activity of SPR741. Antimicrob. Agents Chemother. 2017, 61, e00200-17. [CrossRef]

11. Puño-Sarmiento, J.; Anderson, E.M.; Park, A.J.; Khursigara, C.M.; Barnett Foster, D.E. Potentiation of antibiotics by a novel antimicrobial peptide against Shiga toxin producing E. coli O157:H7. Sci. Rep. 2020, 10, 10029. [CrossRef]

12. Baker, K.R.; Jana, B.; Hansen, A.M.; Nielsen, H.M.; Franzyk, H.; Guardabassi, L. Repurposing azithromycin and rifampicin against Gram-negative pathogens by combination with peptidomimetics. Front. Cell Infect. Microbiol. 2019, 9, 236. [CrossRef]

13. Yang, X.; Goswami, S.; Gorityala, B.K.; Domalaon, R.; Lyu, Y.; Kumar, A.; Zhanel, G.G.; Schweizer, F. A tobramycin vector enhances synergy and efficacy of efflux pump inhibitors against multidrug-resistant Gram-negative bacteria. J. Med. Chem. 2017, 60, 3913-3932. [CrossRef] [PubMed]

14. Idowu, T.; Ammeter, D.; Rossong, H.; Zhanel, G.G.; Schweizer, F. Homodimeric tobramycin adjuvant repurposes novobiocin as an effective antibacterial agent against Gram-negative bacteria. J. Med. Chem. 2019, 62, 9103-9115. [CrossRef] [PubMed]

15. Ramirez, D.; Berry, L.; Domalaon, R.; Brizuela, M.; Schweizer, F. Dilipid ultrashort tetrabasic peptidomimetics potentiate novobiocin and rifampicin against multidrug-resistant Gram-negative Bacteria. ACS Infect. Dis. 2020, 6, 1413-1426. [CrossRef] [PubMed]

16. Zurawski, D.V.; Reinhart, A.A.; Alamneh, Y.A.; Pucci, M.J.; Si, Y.; Abu-Taleb, R.; Shearer, J.P.; Demons, S.T.; Tyner, S.D.; Lister, T. SPR741, an antibiotic adjuvant, potentiates the in vitro and in vivo activity of rifampin against clinically relevant extensively drug-resistant Acinetobacter baumannii. Antimicrob. Agents Chemother. 2017, 61, e01239. [CrossRef]

17. Eckburg, P.B.; Lister, T.; Walpole, S.; Keutzer, T.; Utley, L.; Tomayko, J.; Kopp, E.; Farinola, N.; Coleman, S. Safety, tolerability, pharmacokinetics, and drug interaction potential of SPR741, an intravenous potentiator, after single and multiple ascending doses and when combined with $\beta$-lactam antibiotics in healthy subjects. Antimicrob. Agents Chemother. 2019, 63, e00892-19. [CrossRef]

18. A First in Human Study of the Safety and Tolerability of Single and Multiple Doses of SPR741 in Healthy Volunteers. Available online: https: / / clinicaltrials.gov / ct2/show / NCT03022175 (accessed on 18 January 2022).

19. Vaara, M.; Vaara, T. Sensitization of Gram-negative bacteria to antibiotics and complement by a nontoxic oligopeptide. Nature 1983, 303, 526-528. [CrossRef]

20. Liu, T.; Zhu, N.; Zhong, C.; Zhu, Y.; Gou, S.; Chang, L.; Bao, H.; Liu, H.; Zhang, Y.; Ni, J. Effect of N-methylated and fatty acid conjugation on analogs of antimicrobial peptide Anoplin. Eur. J. Pharm. Sci. 2020, 152, 105453. [CrossRef] 
21. Storck, P.; Umstätter, F.; Wohlfart, S.; Dohman, C.; Kleist, C.; Werner, J.; Brandenburg, K.; Zimmermann, S.; Haberkorn, U.; Mier, W.; et al. Fatty Acid Conjugation Leads to Length-Dependent Antimicrobial Activity of a Synthetic Antibacterial Peptide (Pep14-4LF). Antibiotics 2020, 9, 844. [CrossRef]

22. Datta, A.; Kundu, P.; Bhunia, A. Designing potent antimicrobial peptides by disulphide linked dimerization and N-terminal lipidation to increase antimicrobial activity and membrane perturbation: Structural insights into lipopolysaccharide binding. J. Colloid Interface Sci. 2016, 461, 335-345. [CrossRef]

23. Hancock, R.E.W.; Bell, A. Antibiotic uptake into Gram-negative bacteria. Eur. J. Clin. Microbiol. Infect. Dis. 1988, 7, 713-720. [CrossRef]

24. Qian, Y.; Deng, S.; Cong, Z.; Zhang, H.; Lu, Z.; Shao, N.; Bhatti, S.A.; Zhou, C.; Cheng, J.; Gellman, S.H.; et al. Secondary Amine Pendant $\beta$-Peptide Polymers Displaying Potent Antibacterial Activity and Promising Therapeutic Potential in Treating MRSA-Induced Wound Infections and Keratitis. J. Am. Chem. Soc. 2022, 144, 1690-1699. [CrossRef] [PubMed]

25. Li, H.; Hu, Y.; Pu, Q.; He, T.; Zhang, Q.; Wu, W.; Xia, X.; Zhang, J. Novel Stapling by Lysine Tethering Provides Stable and Low Hemolytic Cationic Antimicrobial Peptides. J. Med. Chem. 2020, 63, 4081-4089. [CrossRef]

26. Fernández-Reyes, M.; Díaz, D.; de la Torre, B.G.; Cabrales-Rico, A.; Vallès-Miret, M.; Jiménez-Barbero, J.; Andreu, D.; Rivas, L. Lysine N(epsilon)-trimethylation, a tool for improving the selectivity of antimicrobial peptides. J. Med. Chem. 2010, 53, 5587-5596. [CrossRef] [PubMed]

27. Chan, W.C.; White, P.D. Fmoc Solid Phase Peptide Synthesis: A Practical Approach, 1st ed.; Oxford University Press Inc.: New York, NY, USA, 2000.

28. Domalaon, R.; Malaka De Silva, P.; Kumar, A.; Zhanel, G.G.; Schweizer, F. The anthelmintic drug niclosamide synergizes with colistin and reverses colistin resistance in Gram-negative bacilli. Antimicrob. Agents Chemother. 2019, 63, e02574-18. [CrossRef] [PubMed]

29. Davin-Regli, A.; Pages, J.-M.; Ferrand, A. Clinical Status of Efflux Resistance Mechanisms in Gram-Negative Bacteria. Antibiotics 2021, 10, 1117. [CrossRef]

30. Meletiadis, J.; Pournaras, S.; Roilides, E.; Walsh, T.J. Defining fractional inhibitory concentration index cutoffs for additive interactions based on self-drug additive combinations, Monte Carlo simulation analysis, and in vitro-in vivo correlation data for antifungal drug combinations against Aspergillus fumi. Antimicrob. Agents Chemother. 2010, 54, 602-609. [CrossRef]

31. Hancock, R.E.W. Alterations in outer membrane permeability. Annu. Rev. Microbiol. 1984, 38, 237-264. [CrossRef] [PubMed]

32. Silver, L.L. A gestalt approach to Gram-negative entry. Bioorg. Med. Chem. 2016, 24, 6379-6389. [CrossRef]

33. Ramirez, D.; Berry, L.; Domalaon, R.; Li, Y.; Arthur, G.; Kumar, A.; Schweizer, F. Dioctanoyl Ultrashort Tetrabasic $\beta$-Peptides Sensitize Multidrug-Resistant Gram-Negative Bacteria to Novobiocin and Rifampicin. Front. Microbiol. 2021, $12,803309$. [CrossRef]

34. Zhanel, G.G.; Decorby, M.; Laing, N.; Weshnoweski, B.; Vashisht, R.; Tailor, F.; Nichol, K.A.; Wierzobowski, A.; Baudry, P.J.; Karlowsky, J.A.; et al. Antimicrobial-resistant pathogens in intensive care units in Canada: Results of the Canadian National Intensive Care Unit (CAN-ICU) study, 2005-2006. Antimicrob. Agents Chemother. 2008, 52, 1430-1437. [CrossRef]

35. Hoban, D.J.; Zhanel, G.G. Introduction to the CANWARD study (2007-2011). J. Antimicrob. Chemother. 2013, 68 (Suppl. 1), i3-i5. [CrossRef] [PubMed]

36. The Clinical and Laboratory Standards Institute. Performance Standards for Antimicrobial Susceptibility Testing, CLSI Supplement M100S, 26th ed.; Clinical and Laboratory Standards Institute: Wayne, PA, USA, 2016.

37. Akhoundsadegh, N.; Belanger, C.R.; Hancock, R.E.W. Outer membrane interaction kinetics of new polymyxin B analogs in Gram-negative bacilli. Antimicrob. Agents Chemother. 2019, 63, e00935-19. [CrossRef] [PubMed] 